\title{
LA OBRA DE GOYA COMO INSPIRACIÓN EN EL CINE ESPAÑOL
}

\author{
Joanna Aleksandrowicz \\ Universidad de Silesia en Katowice \\ https://doi.org/10.18778/8220-195-6.11
}

\section{Resumen}

Se distinguen tres tendencias dentro de las referencias de temática goyesca en el cine. La primera se focaliza en el personaje de Goya, presente en la pantalla como protagonista de películas biográficas, así como personaje secundario en el cine histórico. El segundo tema es la Guerra de la Independencia, cuya iconografía aparece frecuentemente también en las narraciones fílmicas que tratan de otros conflictos. La tercera tendencia está relacionada con diversos contextos sociales. Mencionadas referencias temáticas están vinculadas a varios aspectos formales de la adaptación de la pintura a la pantalla. El análisis del material fílmico además permite mostrar cómo ha evolucionado la manera de ver a Goya en su país.

Palabras clave: la pintura en el cine, Francisco Goya, cine español.

Desde hace dos siglos la vida y obra de Francisco Goya inspira a pintores, escultores, escritores, músicos, dramaturgos y poetas. Su fascinante biografía se mezcló con una leyenda. Su obra se convirtió en fuente de diversos motivos que reflejan la España de los siglos XVIII y XIX, y que siguen resultando actuales en la época contemporánea. Por lo tanto, no es de extrañar que las influencias goyescas estén presentes en numerosas películas desde el cine mudo hasta las últimas tendencias del cine actual.

En la obra de Goya, encuentran inspiración directores de varias nacionalidades. Sin embargo, en nuestro artículo vamos a analizar 
solamente películas españolas. Sirviéndonos de la reflexión cinematográfica, podemos mostrar cómo ha evolucionado la manera de ver a Goya en su país (frecuentemente relacionada con transformaciones de índole político) y cómo, también gracias al cine, el artista se ha ido convirtiendo en un icono de lo español.

Cada época tiene su propia imagen de Goya, a la vez reflejada y creada en narraciones fílmicas. Durante el cine mudo, antes de la Guerra Civil, las obras del artista ayudaban a construir una imagen pintoresca de la España de finales del siglo XVIII y principios del siglo XIX, repleta de tramas patrióticas. Las películas de posguerra subordinan la imagen del pintor a la ideología franquista y la presentación de su obra queda reducida a idílicos cuadros costumbristas y tempranas escenas religiosas. Por el contrario, los directores de la oposición buscaron inspiración en las obras tardías del pintor para la realización de sus películas en el ocaso de la dictadura y los años inmediatamente posteriores a la muerte de Franco. Durante democracia, las ansias de confrontación con el arte del gran aragonés no decrecen sino que siguen estando presentes en la reflexión cinematográfica sobre la España del pasado y de la época contemporánea.

En el cine español encontramos 85 obras inspiradas en el arte de Goya. La mayoría son películas de ficción aunque también hay documentales, series de televisión y un largometraje de dibujos animados. Son obras de estilos y géneros diferentes, que reflejan los frecuentes cambios temáticos y estéticos presentes en el arte del pintor.

Se distinguen tres tendencias dentro de las referencias de temática goyesca en el cine. La primera se centra en el personaje de Goya, presente en la pantalla como protagonista de películas biográficas, así como personaje secundario en el cine de temática histórica. A pesar de las ideas de la Ilustración, presentes en la obra del artista, las películas mudas muestran a Goya como un símbolo de lo español frente a las influencias de la cultura francesa (Seguin, 2005: 64-65). Por primera vez Goya aparece en el cine español en el año 1927 en El dos de mayo de José Buchs'1. El artista,

1 La película fue restaurada en la Filmoteca Española. 
encarnado por Antonio Mata, es retratado en la película como un patriota y testigo de la historia nacional, presentada a través del prisma de sus pinturas y grabados. Un año después Buchs rueda Pepe-Hillo² - la biografía del famoso torrero. Según las fuentes, Goya aparecía en una secuencia del filme dibujando una corrida de toros. Aunque no existe confirmación al respecto, podemos suponer que el pintor también estaba presente en la escena de la muerte de Pepe-Hillo en la plaza de toros de Madrid (Águeda Villar, 2001: 70; Sanz Larrey, 2008: 326). La primera película estrictamente biográfica se titula Goya que vuelve y fue dirigida por Modesto Alonso en 1928, en el centenario de la muerte del pintor. La cinta no se conservó, pero, según las noticias de la época, fue "una entretenida fábula amorosa, llena de vigor y gracia, por la que desfilaban numerosos episodios del levantamiento de 1808 y en la que se reflejaba la más destacada labor pictórica del sordo inmortal" (cit. en Rotellar, 1972: 56). En el papel principal apareció otra vez Antonio Mata, elegido por su gran parecido físico con Goya, el cual conocemos a través de sus autorretratos.

Los directores de las películas biográficas retornan frecuentemente a la leyenda romántica de Goya, relacionada con su supuesto carácter impulsivo, trastornos mentales y con el amor no correspondido por la duquesa de Alba. El mito, inventado por los románticos franceses e ingleses y popularizado por numerosos escritores y poetas, está presente en la mayoría de las biografías fílmicas del pintor. Uno de los ejemplos tempranos de esta tendencia es el guion La duquesa de Alba y Goya, escrito por Luis Buñuel en 1927 y finalmente no realizado.

Durante el franquismo Goya aparece en la pantalla como un personaje secundario, un amigo de majas, actrices y toreros. En el 1969 salió la primera de varias series de televisión sobre el artista, titulada Francisco de Goya. La serie, acorde con la ideología dominante, presenta al pintor como una persona religiosa y preocupada por su familia (Palacio, 2005: 50-51). En cambio, la película Goya, historia de una soledad (1971) de Nino Quevedo vuelve a la

2 Un fragmento de 25 minutos de la película se puede ver en la Filmoteca Española. 
visión romántica. El pintor (Francisco Rabal) es retratado aquí como un genio solitario, enamorado sin correspondencia de la duquesa de Alba y aislado de la sociedad por su sordera y la visión artística incomprensible para sus contemporáneos. José Ramón Larraz, el director de la serie Goya (1985), también muestra al pintor (Enric Majo) como un hombre impulsivo y rebelde. Además de esta historia de amor, en la serie regresa el tema de la identidad nacional, relacionado con las obras goyescas sobre la Guerra de la Independencia.

Del cine de los años noventa cabe destacar la película Volavérunt (1999) de Bigas Luna, basada en la novela homónima de Antonio Larreta (Larreta, 1980). El pintor (Jorge Perugorría) no es aquí solamente uno de los amantes de la duquesa, sino también un astuto observador de las costumbres de la aristocracia y las modas francesas, perdido en el mundo de las intrigas de la corte. En el mismo año Carlos Saura rodó Goya en Burdeos, la más compleja de las biografías cinematográficas sobre el artista. Como afirma el propio director, es una imagen muy personal (cit. en Cánovas Belchí, 2005: 88). Además, la visión ofrecida por el cineasta se ve filtrada por la mirada de su hermano -el pintor Antonio Sauraa quien dedica la película, estrenada poco después de su muerte (Berthier, 2008: 121). El director presenta varios aspectos de la personalidad y del arte de Goya, las influencias artísticas y los cambios de estilo. En las escenas oníricas, el viejo maestro (Francisco Rabal) se encuentra con su joven alter ego (José Coronado) para discutir con él sobre las ideas políticas y la pintura.

Al principio del siglo XXI Luís Eduardo Aute realiza una excepcional película de dibujos animados Un perro llamado Dolor (2001), cuya estructura consta de siete relatos que tratan de los artistas y sus modelos. En el episodio titulado Haberlas... haylas el director vincula la vida de Goya con su arte -sobre todo con el mundo fantástico de los Caprichos (1796-1799)- subrayando el contraste entre la belleza y la muerte, muy presentes en la obra tardía del pintor.

El segundo tema destacado en las reminiscencias temáticas es la Guerra de la Independencia, cuya iconografía aparece en varias películas y series históricas. Una de las obras citadas con 
más frecuencia en la pantalla es el cuadro El tres de mayo de 1808 (1808-1814), símbolo del levantamiento en Madrid ${ }^{3}$. Así mismo, los cineastas vuelven repetidamente al ciclo de grabados Los desastres de la guerra (1810-1815) - considerado como primera imagen realista de la guerra en el arte. Este ciclo, sirvió por ejemplo como punto de partida para la creación de una serie de televisión homónima, dirigida por Mario Camus en 1983 y ambientada en los tiempos de Goya 4 .

Es interesante que la iconografía goyesca de la Guerra de la Independencia aparezca a menudo en las narraciones fílmicas que tratan sobre otros conflictos. En su película Tango (1998) Carlos Saura presenta los grabados del ciclo Los desastres de la guerra en el contexto de la dictadura en Argentina en los años 1976-1982. Sin embargo, la mayoría de las películas vincula los iconos goyescos de la Guerra de la Independencia a las imágenes fílmicas de la Guerra Civil Española. Por ejemplo, en la obra de Antonio Mercero La hora de los valientes un empleado de Museo del Prado oculta en su casa un autorretrato de Goya, que se perdió durante la evacuación. Al final de la película el protagonista muere fusilado por los franquistas siendo la escena una versión moderna del famoso cuadro. Además, aquí el propio autorretrato se convierte en un amigo a quien confiesa sus problemas $y$, a la vez, en testigo de la violencia.

El cine contemporáneo relaciona también algunos frescos de las Pinturas negras con el tema de guerra. Un buen ejemplo es El laberinto del Fauno (2006) de Guillermo del Toro, donde el director utiliza el Saturno (1820-1823) goyesco como metáfora del franquismo y de la Guerra Civil Española. El horroroso personaje

3 Las escenas inspiradas en este cuadro las podemos encontrar por ejemplo en: El dos de mayo, Agustina de Aragón (1950, J. de Orduña), El fantasma de la libertad (Le fantôme de la liberté, 1974, L. Buñuel), Goya, historia de una soledad, Goya, „Ay, Carmela! (1990, C. Saura), La hora de los valientes (1998, A. Mercero), La niña de tus ojos (1998, F. Trueba), Goya en Burdeos, Un perro llamado Dolor, Sangre de mayo (2008, J.M. Garci), El tres de mayo (2009, F.M. Ferrández).

4 En la serie aparece también el personaje de Goya, encarnado por Francisco Rabal. 
del Hombre Pálido devora aquí a las pequeñas hadas, que representan el mundo de la fantasía y la inocencia, pero el sentido simbólico del cuadro lo podemos percibir así mismo en el personaje del capitán franquista - un peculiar alter ego del monstruo.

En la última y tercera tendencia, aparecen varios contextos sociales que van desde el retrato de reyes o de la aristocracia hasta escenas cotidianas como la representación de la pobreza y la superstición. Entre los temas sociales goyescos podemos encontrar también entre otros, motivos religiosos, la Inquisición, las corridas de toros, el matrimonio infeliz o la prostitución.

Desde el cine mudo hasta los años cincuenta del siglo XX, en las películas de temática goyesca predominan las imágenes de corridas de toros y las escenas de bailes idílicos, juegos y paseos a la orilla del río Manzanares ${ }^{5}$. En los años setenta Carlos Saura realiza sus filmes Ana y los lobos (1972) y Mamá cumple cien años (1979). El director considera que el personaje de la madre despótica, que destruye la vida de sus hijos en las dos películas, es la influencia indirecta del Saturno y una alusión a los tabús sociales de la España franquista (Willem, 2003: 165). Otra importante película del periodo es El fantasma de la libertad de Luis Buñuel, llamada "un manifiesto que postula tres principios básicos en la vida y obra del cineasta: la religión, la decadencia burguesa y el concepto de libertad. Estos principios también están fuertemente presentes en la obra de Goya" (Cadafalch, Grandas, 1996: 482). Como explica Eduard Arumí en su análisis sobre las inspiraciones goyescas en el cine de Saura y Buñuel: "lo que nos recuerda de Goya en estas películas no son sólo los temas, sino también la forma de exponerlos: el tono burlesco, irónico, demencial, grotesco, impactante" (Arumí, 1996: 257).

5 Los ejemplos tempranos de esta tendencia son La condesa María (1928, B. Perojo) de la cual no se ha conservado la secuencia inspirada en los cartones de Goya y el anteriormente comentado Pepe-Hillo. En los años cuarenta y cincuenta aparecen películas como: Goyescas (1942, B. Perojo), La maja del capote (1943, F. Delgado), María Antonia La Caramba (1950, A. Ruiz Castillo) y La Tirana (1958, J. de Orduña). 
En la década posterior, la penetrante crítica social de los grabados de Goya regresa bajo la óptica del esperpento en Divinas palabras (1987) de José García Sánchez, basada en el drama de Ramón del Valle-Inclán (Valle-Inclán, 1920). La adaptación puede ser considerada como un buen ejemplo de la inspiración intelectual en el arte de Goya, que está presente en el significado de las escenas, pero sin referencias concretas a nivel visual (Aleksandrowicz, 2009: 113). Por otro lado, Luis García Berlanga se refiere al retrato de la familia real en su película Patrimonio nacional (1981), donde las referencias goyescas están relacionadas con los estereotipos de España y con los cambios socio-culturales de la Transición española.

La reflexión social inspirada en el arte de Goya, aparece también en la obra de Bigas Luna. Su película Caniche (1979) es una sátira contemporánea, basada en los grabados de la serie $\mathrm{Ca}$ prichos, siendo el perro que da nombre al título, una alusión al animal doméstico de la duquesa de Alba, que aparece haciendo compañía a la aristócrata en el famoso retrato del vestido blanco. Veinte años después, en su película Jamón, jamón el director reinterpreta una de las Pinturas Negras, titulada Duelo a garrotazos (1820-1823). La pintura, analizada frecuentemente como un símbolo de la guerra y de la violencia ciega, aparece en la película como un comentario irónico sobre el machismo español. En la escena final los dos protagonistas se baten en duelo y en lugar de palos usan unos jamones ibéricos.

Igualmente en el cine de principios del siglo XXI podemos encontrar referencias irónicas, como el cortometraje de Gonzalo Crespo Gil La oficina (2009), donde El albañil herido (1786-1787) de Goya es relacionado con la situación actual en el mercado laboral. Sin embargo, las inspiraciones goyescas aparecen también en el contexto de las inquietudes artísticas de los jóvenes pintores en la película Castillos de cartón (2009) de Salvador García Ruiz, basada en la novela homónima de Almudena Grandes (Grandes, 2004). En cambio, en Elegía (2008) de Isabel Coixet encontramos una interesante reinterpretación contemporánea del cuadro $L a$ maja desnuda (1797-1800), vinculado aquí al tema de la belleza frágil y el paso del tiempo. En una de las escenas la protagonista, 
enferma de cáncer, posa para su última fotografía desnuda en la posición de la maja goyesca. A veces los directores sitúan las obras en contextos todavía más alejados del original, inscritos en esquemas genéricos. Por ejemplo, en uno de los capítulos de la serie policiaca Génesis (2006-2007) el asesino de serie utiliza Los desastres de la guerra como un macabro modelo para sus crímenes.

De tal distinción sobre las reminiscencias temáticas, se diferencian tres funciones principales de las inspiraciones pictóricas en el cine, estas son: el aspecto biográfico, la utilización de la obra para transmitir el ambiente de la época en las películas históricas y la presencia del cuadro en distintos contextos, que confiere a las obras nuevas $-\mathrm{y}$ a menudo sorprendentes- connotaciones.

Mencionadas referencias temáticas están vinculadas a varios aspectos formales de la adaptación de la pintura a la pantalla. Destacan aquí problemas como: las referencias a los retratos en la creación de personajes históricos, el papel del attrezzo extraído de los cuadros, las funciones del escenario en la obra del artista y su influencia en la construcción del espacio fílmico. Además, hay que considerar las cuestiones estéticas: la composición del encuadre, el problema del marco, los matices del color y el claroscuro.

Las inspiraciones goyescas comentadas representan también tipos particulares de referencias pictóricas en el cine (Aleksandrowicz, 2012: 273-285). El primer tipo, llamado tableau vivant ${ }^{6}$ significa la repetición de la composición del cuadro con todos (o casi todos) los elementos. Punctum intertextual consiste en el uso de los motivos característicos del cuadro en un contexto distinto, lo que crea una alusión menos directa. Otro tipo, llamado quasi-cita, es una composición que remite a un estilo pictórico, pero sin hacer referencia a una obra existente. La más compleja de todas parece la concepción del cine-pintura. Se trata de largas secuencias fílmicas que recuerdan a cuadros o estéticas pictóricas, adaptando sus efectos de color, claroscuro, perspectiva u otros elementos visuales. Todos estos tipos han ido cambiando a lo largo de la historia del cine y generalmente van desde la litera-

6 Conocido también como 'efecto cuadro' o 'cuadro viviente' (Barrientos Bueno, 2008: 19; Ortiz, Piqueras, 1995: 165-167). 
lidad de lo reproducido en la pantalla hasta las referencias mucho más sutiles que representan un tipo de juego intertextual con el espectador.

Las transformaciones estéticas y los significativos cambios de contexto, que podemos observar en las referencias goyescas, no dejan de confirmar la universalidad de la visión artística de Goya. Seguramente en las próximas décadas aparecerán otras películas inspiradas en la obra del pintor, mientras que los cambios culturales y socio-políticos crearán nuevos contextos interpretativos.

\section{Bibliografía}

Águeda Villar, M. (2001). "Goya en el relato cinematográfico". Cuadernos de Historia Contemporánea, 23, 67-101.

Aleksandrowicz, J. (2009). "Pomiędzy płótnem a ekranem. Śladami Goi w kinie hiszpańskim”. Kwartalnik Filmowy, 65, 96-116.

Aleksandrowicz, J. (2012). Pomiędzy płótnem a ekranem. Inspiracje twórczościa Goi w kinie hiszpańskim. Katowice: Wydawnictwo Uniwersytetu Śląskiego.

Arumí, E. (1996). "Goya, artista revolucionario y su influencia en el cine”. Filmhistoria, 6/3, 247-276.

Barrientos Bueno, M. (2008). "Claroscuros de guerra junto a un veterano: Goya y «La hora de los valientes»", Quaderns de Cine: Cine y memoria histórica, 3, 15-21.

Berthier, N. (2008). "Carlos Saura o el arte de heredar", en P. Feenstra y H. Hermans (dir.). Miradas sobre pasado y presente en el cine español (1990-2005), 117-132. Amsterdam-New York: Rodopi.

Cadafalch, C., Grandas, C. (1996). “Goya y su influencia en el cine español de postguerra: una aproximación a través de los directores B. Perojo, J. Orduña y L. Buñuel”, en Goya 250 años después, 1746-1996, 479-490. Marbella: Museo del Grabado Español Contemporáneo.

Cánovas Belchí, J. (2005). "Estragos de la guerra: Goya en el cine de Carlos Saura”, en J.-P. Aubert y J.-C. Seguin (eds.). De Goya à Saura: échos et résonances, 83-92. Lyon: Le Grimh. 
Grandes, A. (2004). Castillos de cartón. Barcelona: Tusquets Editores.

Larreta, A. (1980). Volavérunt. Barcelona: Editorial Planeta.

Ortiz, Á., Piqueras, M.J. (1995). La pintura en el cine. Cuestiones de representación visual. Barcelona: Paidós.

Palacio, M. (2005). "Les images de Goya à la télévision espagnole", en J.-P. Aubert y J.-C. Seguin (eds.). De Goya à Saura: échos et résonances, 49-59. Lyon: Le Grimh.

Rotellar, M. (1972). Aragoneses en el cine, Vol. 3. Zaragoza: Ayuntamiento de Zaragoza.

Sanz Larrey, G. (2008). El dos de mayo y la Guerra de la Independencia (1808-1814) en el cine. Madrid: Consejería de la Cultura y Turismo de la Comunidad de Madrid.

Seguin, J.-C. (2005). “Goya au cinéma”, en J.-P. Aubert y J.-C. Seguin (eds.). De Goya à Saura: échos et résonances, 61-82. Lyon: Le Grimh.

Valle-Inclán, R. del (1920). Divinas palabras. Madrid: Tip. Yägues. Willem, L.M. (2003). Carlos Saura: Interviews. Jackson: University Press of Mississippi. 